\title{
ENTRE A MEMÓRIA E O EXÍLIO: UMA LEITURA DE BARTOLOMEU CAMPOS DE QUEIRÓS
}

\author{
Fábio Ávila Arcanjo ${ }^{1}$
}

Resumo: o presente trabalho tem como objeto de estudo a produção fílmica romena "A leste de Bucareste", lançada nos cinemas no ano de 2005. Dezesseis anos após a revolução de 1989, Virgil Jderescu convida dois debatedores para discutir a questão chave que norteará seu programa de televisão: houve ou não houve uma revolução em nossa cidade? Diante desse enredo, julgamos interessante conjugar alguns postulados teóricos, no sentido de entender algumas questões instigantes como: a importância do processo de rememoração e a dinâmica existente entre a memória individual e a memória coletiva. Para tanto, utilizamos alguns autores importantes: para examinar o conceito de revolução, nossa principal referência é a filósofa alemã Hannah Arendt. No que diz respeito às questões relacionadas à enunciação, utilizamos os trabalhos de autores como Patrick Charaudeau e José Luiz Fiorin. Por fim, para discutir a memória, nossa principal base teórica foi Halbwachs (2015) e Pollak (1989).

Palavras-chave: Cinema; Enunciação; Revolução; Memória.

Abstract: This work has as object of study the Romanian filmic production "East of Bucharest", released in cinemas in 2005. Sixteen years after the 1989 revolution, Virgil Jderescu invites two debaters to discuss the key issue that will guide his television show: Was there or was there not a revolution in our city? Faced with this scenario, we find it interesting to conjugate some theoretical postulates, in the sense of understanding some thought-provoking questions such as: the importance of the remembrance process and the dynamics existing between individual memory and collective memory. To this end, we will use some important authors: to examine the concept of revolution, our main reference is the German philosopher Hannah Arendt. With regard to the questions related to the enunciation, we use the works of authors such as Patrick Charaudeau and José Luiz Fiorin. Finally, to discuss memory, our main theoretical basis was Halbwachs (2015) and Pollak (1989).

Keywords: Cinema; Enunciation; Revolution; Memory.

1 Doutorando do Programa de Pós-Graduação em Estudos Linguísticos da Universidade Federal de Minas Gerais.

E-mail: fabioarcanjo1981@hotmail.com 


\section{INTRODUÇÃO}

O olhar sobre o passado, certamente, é o movimento mais profícuo percorrido por cineastas ao longo da história. Ao adotarmos o conceito de enunciação fílmica, que seria o acionamento no fio do discurso das categorias tempo, pessoa e espaço, somos imediatamente direcionados para aquilo que Fiorin (2016) nomeia de embreagem temporal. Na supracitada obra, o pesquisador brasileiro chama a atenção para a importância de compreender os efeitos de sentido engendrados pelas categorias destacadas anteriormente, sendo o mecanismo da embreagem temporal uma ferramenta fundamental para abordar obras fílmicas que primaram em examinar as cicatrizes e feridas consequenciais à vigoração de regimes autoritários e totalitários.

O que seria esse mecanismo? A palavra-chave para o entendimento de seu funcionamento é presentificação. Quando o sujeito comunicante (Charaudeau, 2012), ser social e agente que opera a articulação da fala, lança mão desse estratagema, pode-se afirmar que ele "resgatou o tempo das brumas da memória e recolocou-o lá novamente" (FIORIN, 2016, p. 43). Em nosso trabalho, cujo corpus será apresentado mais à frente, além dos conceitos mencionados, é válido evocar algo que podemos considerar como primordial na compreensão dos efeitos de sentido almejados pela enunciação fílmica, qual seja, a discursivização. "Assim, a discursivização é o mecanismo criador da pessoa, do espaço e do tempo da enunciação e, ao mesmo tempo, da representação actancial, espacial e temporal do enunciado" (GREIMAS; COURTÉS, 1979, p. 79 apud FIORIN, 2016, p. 37).

Desse modo, a enunciação está atrelada às condições de produção do discurso fílmico, podendo ser caracterizada como o espaço externo de uma situação de comunicação (Charaudeau, 2012). Esse é o espaço de atuação do sujeito comunicante, no qual, mediante a intervenção dos imaginários sociodiscursivos ${ }^{2}$, ele desenvolve as estratégias comunicativas para estruturar seu projeto de fala: que tipo de filme será desenvolvido? Qual será o gênero? Qual será o tom adotado? Em que época ele se passará? Que tipos de ferramentas cinematográficas ele lançará utilizará? Quais os valores e crenças a serem transmitidos pela hipotética obra? Por outro lado, o enunciado seria o chamado fio do discurso, lugar de existência da narrativa fílmica, onde interagem as personagens e os cenários. As questões apresentadas anteriormente encontrariam ressonância no enunciado, se inscrevendo no espaço interno da situação de comunicação.

Veremos ao longo de nosso texto que os conceitos apresentados anteriormente se mostram fundamentais para a análise dos efeitos de sentido almejados pelo cineasta. Após esse longo introito, acreditamos ter chegado o momento de apresentar o nosso corpus.

Em 2005, chega aos cinemas o filme "A leste de Bucareste", dirigido por Corneliu Porumboiu, que rapidamente se transformou em sucesso de crítica, principalmente por abor-

2 "Esse lugar é o da organização dos saberes em que é realizada a demarcação das ideias e dos valores [...]. À medida que esses saberes, enquanto representações sociais, constroem o real como universo de significação, segundo o princípio de coerência, falamos de 'imaginários'. E tendo em vista que estes são identificados por enunciados linguageiros produzidos de diversas formas, mas semanticamente reagrupáveis, nós os chamamos de 'imaginários discursivos'. Enfim, considerando que circulam no interior de um grupo social, instituindo-se em normas de referência por seus membros, falaremos de 'imaginários sociodiscursivos”' (CHARAUDEAU, 2013, p. 203). 
dar uma temática árida e espinhosa com leveza e ironia, mas sem vulgarizar uma discussão política significativa, como a queda de um regime totalitário. O filme em questão discursiviza, através da comédia, o fim da ditadura instituída pelo líder romeno Nicolae Ceausescu. São três as personagens principais: Virgil Jderescu, um apresentador de um programa de televisão chamado "Assunto do dia"; Tiberiu Manescu, um professor de história frustrado e com problema de alcoolismo; e Emanoil Piscoci, um senhor aposentado, famoso no bairro pelos anos em que se vestia de Papai Noel.

Para sermos mais exatos, o que a produção apresenta não é bem a discursivização do término do regime totalitário de Ceausescu (em vigor de 1965 a 1989), mas, sim, o papel que uma pequena cidade - nunca mencionada durante a projeção, que fica, como o título bem nos informa, a leste de Bucareste, ou seja, à margem dos grandes centros - teve durante a Revolução que destituiu o regime totalitário naquele país. Em 17 de dezembro de 1989, na cidade de Timisoara ocorreu uma grande manifestação contra o governo de Ceausescu, reprimida com violência pela Securitate (força policial do regime). Poucos dias depois, a ação dos manifestantes se espalha por toda a Romênia, chegando à Bucareste, onde, no dia 22 de dezembro de 1989, funcionando quase como uma antecipação do presente de natal, temos o fim do regime, quando Ceausescu entrega o cargo.

Diante do que foi apresentado, é válido nos perguntarmos a respeito da inserção de "A leste de Bucareste" nesse quadro. Eis a resposta: 16 anos mais tarde, quando Virgil Jderescu resolve debater, em seu programa de televisão, o papel que sua cidade teve na revolução de 1989. A pergunta-chave a ser discutida em “Assunto do dia” é: houve, verdadeiramente, uma revolução na pequena cidade situada a leste de Bucareste?

\section{ENUNCIAÇÃO FÍLMICA}

Para Charaudeau (2012), o modo de organização enunciativo direciona o foco para os protagonistas - seres de fala - inseridos no espaço interno de linguagem. O autor no explica que

o verbo enunciar se refere ao fenômeno que consiste em organizar as categorias da língua, ordenando-as de forma a que deem conta da posição que o sujeito falante ocupa em relação ao interlocutor, em relação ao que ele diz e em relação ao que o outro diz (CHARAUDEAU, 2012, p. 82. Destaques do autor).

Isto posto, é importante apresentar o procedimento de enunciação fílmica, fruto de um ato de linguagem instaurado pelo sujeito-da-câmera, o cineasta, propriamente dito, que conjuga os dois espaços de linguagem, o externo - voltado para a posição que o sujeito falante ocupa - e o interno - estruturado através da dinâmica narrativa construída por esse sujeito. A enunciação fílmica trabalha em duas frentes, no que diz respeito ao acionamento da tríade dêitica pessoa, tempo e espaço através da discursivização: no processo de enunciação, responsável pela criação das categorias citadas; e na organização do mecanismo de representação actancial, espacial e temporal do enunciado. 
Em "A leste de Bucareste" temos, portanto, o nível da enunciação, mobilizado pelo sujeito-da-câmera Corneliu Porumboiu, com o apoio de toda a sua equipe técnica - pensando na categoria pessoa -, amparado pelos valores e crenças vigentes em seu país - articulados pelas categorias tempo e espaço. Já no nível do enunciado, somos levados aos três personagens principais Virgil Jderescu, Tiberiu Manescu e Emanoil Piscoci - nível actancial -; que interagem espacialmente na pequena cidade situada a leste de Bucareste; cuja representação temporal acaba sendo impulsionada por uma efeméride: 16 anos de comemoração da revolução de 1989.

Por se tratar de uma produção cujo foco é a rememoração de uma data marcante, é relevante compreender como se dá o mecanismo de embreagem temporal na produção de Corneliu Porumboiu. É essencial ressaltar que esse tipo de artifício pode ser utilizado de diversas maneiras. No gênero documentário, por exemplo, ele pode se inscrever no fio do discurso fílmico através das imagens de arquivo e das rememorações operadas pelos atores sociais $^{3}$, caso estejamos falando de um tipo de produção cujo foco principal seja a interação entre documentarista e entrevistado. Nas produções ficcionais, também é possível pensar na presença de imagens de arquivo, principalmente nos chamados docudramas ${ }^{4}$. Além disso, em tais filmes a embreagem temporal pode surgir através de flashbacks e através de rememorações, que ocorrem na dinâmica narrativa estabelecida entre as personagens. É nessa última que podemos situar a produção analisada pelo presente artigo. Em "A leste de Bucareste" não temos a presença de flashbacks. O passado irrompe no presente através da fala dos personagens, sendo precisamente esse o principal ponto de articulação da representação temporal conduzida por Corneliu Porumboiu.

Como estamos falando de personagens, é pertinente, voltando o olhar para o espaço interno da situação de comunicação, trazer algumas questões relativas ao modo de organização narrativo. Novamente, precisaremos nos municiar das contribuições oferecidas pelo linguista francês Patrick Charaudeau:

Contar é uma atividade posterior à existência de uma realidade que se apresenta necessariamente como passada (mesmo quando é pura invenção), e, ao mesmo tempo, essa atividade tem a propriedade de fazer surgir, em seu conjunto, um universo, o universo contado, que predomina sobre a outra realidade, a qual passa a existir somente através desse universo [...]. Contar é também construir um universo de representações das ações humanas por meio de um duplo imaginário baseado em dois tipos de crenças que dizem respeito ao mundo, ao ser humano $e$ à verdade. (CHARAUDEAU, 2012, p. 154. Destaques do autor).

No excerto antecedente, existem questões que se mostram fulcrais para a discussão presente na produção fílmica romena, com destaque para a menção à ideia de verdade, ter-

3 Terminologia utilizada por Bill Nichols (2014) para caracterizar a figura do entrevistado ou da personagem do documentário.

4 Segundo Fernão Pessoa Ramos, "a ficção baseada em fatos históricos, ou docudrama, possui todas as características narrativas de uma ficção, conforme a narrativa ficcional se configurou na história do cinema. Para representar fatos históricos, o docudrama usa estruturas narrativas marcadas pelo classicismo hollywoodiano. Não é um documentário, pois não enuncia como enunciam os documentários” (RAMOS, 2013, p. 51). 
mo controverso, principalmente por estarmos lidando com um discurso memorialístico. Susan Rubin Suleiman observa que "as cerimônias públicas de comemoração sempre envolvem uma instrumentalização da memória e uma interpretação dos fatos à luz de objetivos políticos atuais" (SULEIMAN, 2019, p, 89). Os termos instrumentalização e interpretação mostram, de forma decisiva que não estamos diante de uma verdade pura e inexorável. Charaudeau (2012), mesmo, enfatiza isso no fragmento selecionado, uma vez que ele observa a presença de dois tipos de crenças: a unicidade do ser (narrativas inalteráveis, alegóricas e que idealizam heróis) e a crença em uma realidade plural.

É importante afirmar que a memória lança mão dos dois tipos de crenças, construindo um horizonte de compartilhamento, isto é, um imaginário sociodiscursivo. Contudo, acreditamos que a segunda crença seja mais instigante, principalmente por apresentar pontos de contato com o conceito de memória coletiva. "O mundo, ao contrário, seria fragmentado numa materialidade lacunária sem começo e fim, e o ser seria partido numa multiplicidade de parcelas de existência das quais não se percebe nunca o todo" (CHARAUDEAU, 2012, p. 155).

Como não deixar de pensar na memória coletiva como uma espécie de aglutinador de imaginários marcado pelo caráter lacunar? "A memória coletiva é não somente uma conquista, é também um instrumento e um objeto de poder" (LE GOFF, 1992, p. 470). O próximo fragmento, a nosso ver, é fundamental para entender o mecanismo enunciativo presente em "A leste de Bucareste", pois, a partir dele, tornar-se-á patente a concepção de herança, que, muitas vezes, pode incorrer em lapsos ou, até mesmo, em distorções.

\begin{abstract}
Para que a nossa memória se aproveite da memória dos outros, não basta que estes nos apresentem seus testemunhos: também é preciso que ela não tenha deixado de concordar com a memória deles e que existam muitos pontos de contato entre umas e outras para que a lembrança que nos fazem recordar venha a ser reconstituída sob uma base comum (HALBWACHS, 2015, p. 39).
\end{abstract}

Ao trazer para seu programa dois entrevistados, cujos depoimentos serão, em alguns momentos, severamente confrontados por espectadores que participarão por telefone, Virgil Jderescu objetiva trabalhar a memória coletiva a partir de um evento definidor dos rumos tomados por seu país após 1989. Interessante destacar o trecho no qual o autor teoriza a respeito da retroalimentação realizada pela memória, isto é, a nossa memória se aproveitando da memória dos outros. O que Halbwachs quer destacar é a construção de uma memória coletiva a partir de um horizonte de compartilhamento. Em "A leste de Bucareste", ao contrário, o termo "aproveitar" atinge um horizonte semântico mais negativo, pois o que vemos é um conflito entre memórias. Não parece haver um consenso entre os debatedores e os espectadores.

A ausência de consenso se deve à falta de legitimidade dos participantes do programa, pois as personagens em questão se mostram destituídas daquilo que podemos nomear de notório saber. Mesmo o professor de história, uma profissão que legitimaria sua participação em uma discussão tão profunda, acaba sendo alguém cujo saber é constantemente des- 
construído. E isso se dá pela construção narrativa desenvolvida por Cornélio Porumboiu. As aulas dadas por Tiberiu Manescu se mostram absolutamente confusas e o que se percebe é um professor mais preocupado em alimentar seus vícios do que instruir seus alunos.

Portanto, é primordial perceber que a instrumentalização da memória, de que fala Susan Suleiman, emerge na produção romena, de forma tácita. É claro que os acontecimentos da revolução de 1989 foram instrumentalizados pela memória coletiva, ou, melhor dizendo, pela memória oficial. Entretanto, a comemoração dos 16 anos da queda do regime ditatorial, no filme em questão, está longe de ser um evento relevante, justamente pelo suporte dado a ela - uma pequena televisão local, situada em uma cidade "sem nome", com a participação de personagens alheias aos saberes de conhecimento (Charaudeau, 2013) legitimados pela memória oficial.

Diante do exposto, é pertinente nos perguntarmos: já que o verbo principal do modo de organização narrativo é contar, como Cornélio Porumboiu pretende conjugar tal verbo? O que ele procura problematizar em sua obra? Lembrando que a enunciação e o enunciado compartilham o mesmo espaço temporal (o ano de 2005) e nesse sentido, suspeitamos que os mesmos anseios de Virgil Jderescu são compartilhados pelo cineasta romeno. Um ponto que se mostra interessante diz respeito à pergunta-chave que conduz todas as interações presentes durante o programa televisivo: houve, verdadeiramente, uma revolução na pequena cidade situada a leste de Bucareste? Para problematizar essa questão, é preciso compreender o que as personagens entendem por revolução e, claro, como a sua existência, ou não, poderia ser ratificada. Quais seriam os critérios selecionados para a existência da revolução? Faremos essa discussão no próximo tópico e para melhor fundamentá-la, buscaremos o auxílio da filósofa alemã Hannah Arendt.

\section{HOUVE OU NÃO HOUVE UMA REVOLUÇÃO NESTA CIDADE?}

Hannah Arendt (2011) relata um impactante diálogo travado entre o duque La Rochefoucauld-Liancourt e o Rei Luís XVI em 14 de julho de 1789, motivado pela queda da Bastilha. O duque, exercendo a função de mensageiro, informa ao rei os acontecimentos mais recentes, com destaque para a famosa insurreição popular. Ao se inteirar sobre o assunto, Luis XVI exclama: "C'est une revolte!" e acaba sendo corrigido pelo súdito: "Non, sire, c'est une révolution!”. O que se pode inferir dessa curiosa interação? A filósofa alemã explica que o item lexical revolta traz consigo a possibilidade de reversão, através da confrontação. Contudo, quando se fala em revolução, imediatamente se pensa em um evento marcado, e essa é uma definição de Hannah Arendt (2011), pela irreversibilidade.

Ao resgatar a origem do termo revolução, a autora remete à obra De revolutionibus orbium coelestium, escrita por Copérnico. Existe, aqui, um espírito de regularidade e manutenção, que se apresenta alheia à definição moderna do termo. Arendt (2011) observa que o significado latino do termo evoca a imagem de um movimento regular e obrigatório dos astros em suas órbitas, "o qual, por estar sabidamente fora do alcance do homem, sendo por isso irreversível, certamente não se caracteriza pela novidade nem pela violência” (ARENDT, 2011, p. 72). A autora complementa: 
O movimento ainda reflete a imagem do ciclo dos astros, mas o que agora se destaca é que está além das forças humanas poder detê-lo, e por isso é uma lei em si mesmo. O rei, ao declarar que o assalto à Bastilha era uma revolta, afirmava seu poder e os vários meios de que dispunha para enfrentar constipações e desafios à autoridade; Liancourt respondeu que o que havia acontecido era irreversível e ultrapassava os poderes de um rei (ARENDT, 2011, p. 79).

O evento definidor para aquilo que seria uma espécie de modelo de movimento revolucionário foi a Revolução Francesa, que, segundo Hannah Arendt, trazia em seu início uma raiz restauradora. Contudo, o que seria a principal herança desse movimento, em relação a acontecimentos futuros, foi a impossibilidade de impor resistência a ele, o que acaba culminando em uma espécie de "caminho sem volta". "A noção de um movimento irresistível, que o século XIX logo iria conceitualizar na ideia de necessidade histórica, ressoa em todas as páginas da Revolução Francesa, do começo ao fim” (ARENDT, 2011, p. 80). É necessário abrir um parêntesis que evidenciará a aura de modelo conferida à supracitada revolução: a última aula ministrada por Manescu, antes de participar do programa televisivo, foi uma atividade orientada pelo professor sobre, justamente, a Revolução Francesa. E isso acaba sendo curioso, pois a aula aconteceu, precisamente, no dia em que a Romênia celebrava 16 anos da sua própria revolução, que culminou no fim da ditadura totalitária de Ceausescu.

$O$ fato é que, ao longo do tempo, o conceito de restauração deixou de ser vinculada ao termo revolução. A palavra-chave para entender o espírito revolucionário é liberdade. É claro que esse objetivo pode funcionar como um mero pretexto, qual seja, nas palavras de Arendt (2011), a busca por um novo absoluto. Contudo, independentemente dos rumos consequenciais ao início do movimento revolucionário, o que parece mover os agentes e aqueles que foram levados a aderir à causa acaba sendo a liberdade.

Apenas onde existe esse páthos de novidade e onde a novidade está ligada à ideia de liberdade é que podemos falar em revolução [...]. Apenas quando a mudança ocorre no sentido de criar um novo início, quando a violência é marcada pela busca de uma forma de governo totalmente nova e para gerar a formação de um novo campo político, quando a libertação da opressão visa pelo menos à constituição da liberdade é que se pode falar em revolução (ARENDT, 2011, p. 63-64).

Tomando como base o que foi exposto em linhas anteriores, voltemos o nosso olhar para a produção fílmica "A leste de Bucareste". Nos primeiros planos, vemos algumas ruas desertas e uma série de postes de eletricidade cujas luzes vão, paulatinamente, se apagando. Como não pensar no conceito de esquecimento? Podemos imaginar que as luzes que ainda estão acesas podem funcionar como rastros, que "inscrevem a lembrança de uma presença que não existe mais e que sempre corre o risco de se apagar definitivamente" (GAGNEBIN, 2006, p. 44). Em seguida, temos acesso à rotina de vida das três personagens principais. Esses momentos são interessantes para que o público possa perceber o quão "comuns" são tais personagens, isto é, a discursivização da revolução de 1989 será conduzida por pessoas que se mostram alheias à condição de especialistas. Façamos um corte brusco, rumo à segunda 
metade, pois é, aqui, que se encontra o centro daquilo que é discutido na produção romena. Virgil Jderescu, apresentador do programa "Assunto do dia", abre a atração televisiva de forma contundente:

Boa tarde, senhoras e senhores. Hoje é um dia muito importante para nosso país. Há 16 anos, em dezembro de 1989, houve uma revolução em Bucareste. Uma nova era na história romena. Vamos voltar no tempo para examinar se nós, cidadãos desta cidade, tomamos parte neste momento da história, junto com nossos convidados e telefonemas dos espectadores [...]. Vamos tentar responder uma pergunta que está na minha cabeça há muito tempo. A questão que gostaria de esclarecer hoje é: houve ou não houve uma revolução em nossa cidade?

Em seguida, o jornalista apresenta duas imagens marcantes. A primeira é o Mito da caverna de Platão: "É meu dever como jornalista perguntar se não deixamos uma caverna por outra maior e se não estamos confundindo um fogo de palha com o sol". A questão que se coloca: o que tais palavras trazem como significado? Estaria o apresentador questionando a construção narrativa da revolução de 1989? Ao levar entrevistados, aparentemente, não gabaritados, Jderescu pretende desconstruir a memória oficial ou ele quer mostrar o quão fragmentado pode ser o processo de rememoração?

Em primeiro lugar, acreditamos estar diante de um procedimento de desconstrução, no sentido de que a chave de leitura para a revolução seria a ampla participação popular. Ora, a necessidade de perguntar se, de fato, houve uma revolução em sua pequena cidade demonstra algum tipo de inconsistência. É sabido que houve uma revolução em Timisoara e em Bucareste, ou seja, um debate sobre a existência de um movimento de insurreição nas duas cidades talvez não houvesse razão de ser. Mas na pequena cidade situada a leste de Bucareste - à margem da capital romena, a pergunta acaba fazendo algum sentido.

Sobre os entrevistados, acreditamos não haver a necessidade em explorar o caráter fugidio do procedimento de rememoração, mas, ao contrário, o que se percebe é o pleno funcionamento do procedimento, nomeado por Michael Pollak (1989), de enquadramento.

A memória, essa operação coletiva dos acontecimentos e das interpretações do passado que se quer salvaguardar, se integra, como vimos, em tentativas mais ou menos conscientes de definir e reforçar sentimentos de pertencimento e fronteiras sociais entre coletividades de tamanhos diferentes [...]. A referência ao passado serve para manter a coesão do grupo e das instituições que compõem uma sociedade, para definir seu lugar respectivo, sua complementariedade, mas também as oposições irredutíveis (POLLAK, 1989, p. 9).

Esse rico fragmento tem alguns pontos fundamentais na compreensão da necessidade, ou não, de colocar a pequena cidade romena no mapa do movimento revolucionário de 1989. Manescu, o professor de história, afirma: "conforme o tempo passa, as pessoas esquecem e é uma vergonha. Uma grande vergonha". O que seria vergonhoso, o esquecimento ou a exame de consciência a respeito do papel exercido pela cidade na marcha revolucionária 
romena? Ao que parece, examinando as interações construídas durante o programa, vergonhoso seria não ter participado do movimento, pois isso negaria o pertencimento de que fala Pollak. A revolução de 1989 é um acontecimento que agrega valores, crenças e imaginários a respeito do povo romeno e não ter participado poderia trazer uma crise de identidade, esfacelando a tão almejada coesão do grupo.

A segunda imagem construída por Jderescu diz respeito à famosa frase de Heráclito. Vejamos o que ele nos apresenta:

Creio que não há presente sem passado e não há futuro sem presente. Quanto mais claro o passado, mais claro será o futuro. Por outro lado, Heráclito disse: não se pode pisar no mesmo rio duas vezes. Mas vamos voltar no tempo, para 16 anos atrás, pelo bem da verdade e de um futuro melhor.

A impossibilidade de "pisar no rio duas vezes" diz respeito à inviabilidade de manter o caráter homogêneo, por se tratar de um processo irrepetível. Isso acaba sendo curioso, pois o enquadramento visaria, propriamente, trazer uma coesão narrativa. Nesse sentido, a noção de verdade, conjugada no singular por Virgil Jderescu, acaba sendo problemática, pois a memória oficial, de certa forma, busca uma coerência, abrindo pouco espaço para contingências. Mas seu programa parece querer investigar como se dá a inscrição da memória individual, pois ele convida entrevistados que não participam do chamado debate público. Como tais participantes se enquadram no cenário de uma memória coletiva construída em torno dos ideais revolucionários de 1989 ?

Em "A leste de Bucareste" a pergunta que conduziu as interações foi: "O que você fez em 22 de dezembro de 1989?". Os dois entrevistados afirmaram categoricamente que estavam protestando contra Ceausescu na principal praça da cidade. Jderescu define um critério, uma espécie de marco temporal, para identificar se, de fato, houve uma revolução na cidade. Se as pessoas tivessem ido para a praça antes de $12 \mathrm{~h} 08$, horário em que o ditador romeno deixou o poder, de fato, houve uma revolução. Do contrário, se as praças foram povoadas após esse horário, o que aconteceu foi apenas uma celebração. Ora, a despeito do fato de que é um critério de identificação absolutamente frágil, pois ele não considera o período de germinação dos ideais, iremos desconsiderar essa problematização para focar na construção da imagem de si realizada tanto por Manescu, quanto por Piscoci. Ambos afirmaram, de forma clara, que estavam protestando na praça antes da deposição do ditador.

Contudo, o programa conta com a participação dos espectadores por telefone. E, a partir da primeira ligação, as narrativas construídas pelos debatedores "caem por terra". $\mathrm{O}$ que se vê são espectadores desmentindo os convidados, sendo Manescu o principal alvo das discórdias. Um dos participantes é ainda mais implacável ao dizer: "como pode discutir a nossa querida revolução com este indivíduo idiota [...] um bêbado que suja a nossa reputação". O que fica subentendido, a partir dessa fala, é que não são todos os que podem discutir temas tão sérios como a revolução de 1989. Seriam, portanto os "escolhidos" que confeririam a coesão, que organizariam o enquadramento.

O enunciado fílmico nos impele a acreditar que a fala dos entrevistados é, de fato, enganosa. Não apenas pelos telefonemas que desmentem suas asserções, como pelo perfil 
traçado para tais personagens: um professor viciado em bebidas alcóolicas e um senhor aposentado cuja única ocupação atual é novamente se vestir de Papai Noel. Entretanto, podemos afirmar que, se em nível interno - em termos de narrativa -, a veracidade é importante, pois sua (in) existência proporcionou os debates acalorados presentes no filme, em nível externo - em termos de enunciação - isso não importa tanto. O que se discute em "A leste de Bucareste" é o porquê de os personagens recorrerem às inverdades ou exageros. Por que eles exageram nas "tintas" e "pintam um quadro" no qual seu papel frente à revolução foi criado de forma a exaltar suas participações? Halbwachs (2003) afirma que

os fatos e memórias que mais facilmente recordamos são do terreno comum, pelo menos para um ou alguns ambientes. Essas lembranças existem para "todo o mundo" nesta medida e é porque podemos nos apoiar na memória dos outros é que somos capazes de recordá-las a qualquer momento e quando o desejamos (HALBWACHS, 2003, p. 67).

Aqui, é preciso fazer um arranjo: Partindo do princípio de que Emanoil Piscoci e Tiberiu Manescu enunciaram, não sabemos se consciente ou inconscientemente, inverdades, o que se tem não é bem um apoio na memória dos outros, mas, sim, uma espécie de manipulação dessas memórias. Poderíamos até falar em memória herdada, sedimentada no imaginário sociodiscursivo e discursivizada pelos entrevistados. Entretanto, nos parece mais pertinente identificar pontos de contato com o famoso caso protagonizado por Binjamin Wilkomirski". "A memória de Wilkomirski é uma enorme memória de substituição, deslocada, uma memória 'em lugar e espaço', no lugar de outra e em nome de outra” (ROBIN, 2016, p. 228).

Qual a diferença entre Wilkomirski e as personagens da produção romena? Justamente o fato de elas serem personagens. Portanto, elas estão a serviço de um projeto de fala conduzido por Cornélio Porumboiu. O que se pode notar é que "A leste de Bucareste" visa problematizar a ideia de memória herdada, voltando o olhar para aqueles que podem ser considerados meros coadjuvantes. Como eles podem se inscrever em um cenário de memória oficial? Através de repetições que buscam construir para si uma imagem de revolucionário, de protagonistas, mesmo estando situados a leste de Bucareste, ou seja, à margem dos grandes centros e alheios às grandes e revolucionárias decisões.

\section{CONSIDERAÇÕES FINAIS}

Ao longo da projeção de "A leste de Bucareste", algumas falas se apresentam significativas para justificar o projeto de fala de Virgil Jderescu e, porque não afirmar, do próprio

5 Binjamin Wilkomirski, cujo nome verdadeiro é Bruno Dössekker, é responsável por uma das maiores fraudes, no que diz respeito à literatura de testemunho. Em 1996, ele lança a obra Fragments: memories of a childhood, em que ele alega ter sido um sobrevivente do Holocausto. Inicialmente, a obra fez um enorme sucesso. Anos mais tarde, uma vez desvendada a fraude literária, o livro acaba sendo relegado ao esquecimento. 
diretor romeno, uma vez que a personagem, conforme afirmamos anteriormente, parece dar vazão aos anseios de Cornélio Porumboiu. Uma personagem, por exemplo, afirma: "Por que tanto alvoroço por causa da revolução? Ninguém liga mais pra isso". Outra, que participou por telefone do programa "Assunto do dia", diz algo ainda mais impactante: "Não houve revolução alguma. Era melhor com Ceausescu”. Qual o sentido na inserção de tais falas? O fato é que elas acabam sendo inscrições de fenômenos recorrentes quando se lida com acontecimentos históricos marcantes. O primeiro seria a ação do tempo como um dispositivo que atenuaria aquilo que foi vivenciado. "Ninguém liga mais pra isso" porque, em um passado distante, outras pessoas ligaram e tentaram, de alguma forma, modificar determinado estado de coisas.

A segunda fala destacada é ainda mais preocupante, pois ela se enquadra nos fenômenos do revisionismo e do negacionismo, tão em voga nos dias atuais, que se mostram marcados pela construção de narrativas que visariam justificar governos autoritários e totalitários.

Entretanto, a nosso ver, a discussão mais instigante em "A leste de Bucareste" é a relação entre a memória individual e a memória coletiva, no sentido de que a primeira, em um claro esforço de almejar o pertencimento, isto é, buscando uma afirmação identitária, se enquadraria na segunda. Mesmo que as personagens não tenham, verdadeiramente, sido agentes da revolução, eles compartilham o mesmo imaginário sociodiscursivo, ou seja, as mesmas crenças e valores. As supostas inverdades enunciadas funcionariam como um mecanismo de criação de imagens de si.

Os últimos planos fazem alusão ao que foi dito pela personagem Emanoil Piscoci: "a revolução é como as luzes das ruas. Primeiro, elas acendem no Centro e depois pelo resto da cidade". Na verdade, podemos trocar o termo revolução por rememoração, pois, a nosso ver, Cornélio Porumboiu iluminou uma realidade que se mostrava silenciada, como as luzes apagadas mostradas nos primeiros planos do filme. 


\section{REFERÊNCIAS BIBLIOGRÁFICAS}

ARENDT, Hannah. Sobre a revolução. Tradução de Denise Bottmann. São Paulo: Companhia das Letras, 2011.

CHARAUDEAU, Patrick. Linguagem e discurso: modos de organização. Coordenação da equipe de tradução Angela M. S. Corrêa e Ida Lúcia Machado. 2a ed., 1ª reimpressão. São Paulo: Contexto, 2012.

CHARAUDEAU, Patrick. O discurso político. Tradução de Fabiana Komesu e Dilson Ferreira da Cruz. $2^{\mathrm{a}}$ ed., $1^{\mathrm{a}}$ reimpressão. São Paulo: Contexto, 2013.

FIORIN, José Luiz. As astúcias da enunciação: as categorias pessoa, espaço e tempo. São Paulo: Contexto, 2016.

GAGNEBIN, Jeanne Marie. Lembrar escrever esquecer. São Paulo: Editora 34, 2006.

HALBWACHS, Maurice. A memória coletiva. Tradução de Beatriz Sidou. $2^{\mathrm{a}}$ ed., $8^{\mathrm{a}}$ reimpressão. São Paulo: Centauro, 2015.

LE GOFF, Jacques. História e memória. 2. ed. Tradução de Irene Ferreira (et al). Campinas, SP: Editora da Unicamp, 1992.

NICHOLS, Bill. Introdução ao documentário. Tradução de Mônica Saddy Martins. - $5^{\text {a }}$ Ed. Campinas, SP: Papirus, 2014.

POLLAK, Michael. Memória, história e esquecimento. In: Estudos Históricos. v. 2, n. 3, Rio de Janeiro, 1989, p. 3-15.

RAMOS, Fernão Pessoa. Mas afinal... O que é mesmo documentário? 2a ed. São Paulo: Editora Senac, 2013.

ROBIN, Régine. A memória saturada. Tradução de Cristiane Dias, Greciely Costa. Campinas, SP: Editora da Unicamp, 2016.

FILMOGRAFIA

PORUMBOIU, Cornélio (dir.). A leste de Bucareste (2005, título original: A fost sal n-a fost?), Romênia, cor, $85 \mathrm{~min}$. 